\title{
INFLUENCE OF PLANT TEXTURE ON THE FEEDING CAPACITY AND FECUNDITY OF THE PREDATORY MITE Phytoseiulus persimilis (A. - H.). Nassar, O. A. ${ }^{1}$; A. H. Fouly ${ }^{1}$; R. A. Fouda ${ }^{2}$ and M. A. Osman ${ }^{1}$ 1- Agricultural Zoology Department, Faculty of Agriculture, Mansoura 2- Agricultural Botany Department, Faculty of Agriculture, Mansoura University, Mansoura 35516, Egypt. mesoma20@mans.edu.eg
}

\begin{abstract}
Feeding capacity and fecundity of the predatory mite Phytoseiulus persimilis fed on nymphal stages of the two - spotted spider mites were highly affected by the plant texture and rearing substrates. The predatory mite individually attacked more preys on bean leaves. The feeding capacity during 10 days in the oviposition period was declined gradually on apple, fig, cotton and mango with an average of 16.37 , 15.92, 10.28, 9.95 and 8.97 prey individuals/day, respectively. The statistical analysis proved that there were no significant differences between the values of prey consumption of $P$. persimilis on either bean and apple leaves or fig and cotton leaves, in spite of the differences in morphological characters between the aforementioned plants and the others are significant. Therefore, it can be concluded that both bean and apple leaves are more suitable substrates to rear and maintain $P$. persimilis. Also, egg deposition was significantly decreased when maintained on cucumber and squash leaves. The lowest rates of fecundity were obtained on mango and cotton leaves. Adult female of the predatory mite laid an average of $39.5,37.3$ and 36.1 eggs/10 days with daily rate of $3.95,3.73$ and 3.61 eggs / + / day on bean, apple and fig leaves, respectively, compared to $31.5,30.5,25.6$ and 25.1 eggs / + on squash, cucumber, mango and cotton leaves, respectively.

Among structures differences on the surfaces of leaves not only the venation type and hair density but also the raised veins that play an important role on the number of deposited eggs of predator and its feeding capacity on prey.

$P$. persimilis attacked more prey and laid more eggs on smooth hairy leaves like those of bean and apple while cucumber, squash and cotton leaves are not suitable. Therefore, bean leaves are recommended to maintain $P$. persimilis cultures for biological control purposes.
\end{abstract}

\section{INTRODUCTION}

Few studies done on the Influence of Plant Texture on the Consumption and Fecundity of Phytoseiulus persimilis (A. - H.). Raised viens, dense hairs, tunneled margins and cave - like structures in the vein axils which called domatia, These structures affect searching, feeding, mating, oviposition, hiding and other behaviours of P. persimilis. (Walter, 1996). Leaves with domatia often harbor more phytoseiids or greater densities of a species than leaves without domatia. Such shelters and leaf pubescence, may be as important as food for some phytoseiids (McMurtry and Croft, 1997). Moreover, Skrivin and Fenlon (2001) stated that the leaf morphology is considered to be one of the most important factor affecting predation rate and feeding capacity of $P$. persimilis which attacked more prey individuals on smooth hairy leaves. Therefore the present work aims to study 
Nassar, O. A. et al.

effect of different Plant Texture on the Consumption and Fecundity of Phytoseiulus persimilis (A. - H.)

\section{MATERIALS AND METHODS}

For studying the effect of plant texture on the feeding capacity and fecundity of $P$. persimilis, seven types of plant texture Bean Phaseolus vulgaris L., Apple Malus Sylvesters L., Fig Ficus carica L., Squash Cucurbita pepo L., Cucumber Cucumis satirus L., Mango Mangifera indica L. and Cotton Gossypium barbadens L. were used. From each one small plant leaf discs ( 1 inch each) were taken and kept on moist cotton pad in petri dishes $(15 \mathrm{~cm}$ in diameter). Pure culture of the predatory mite $P$. persimilis was obtained from IRC. Cairo, Egypt. Newly emerged females of the predator were divided into seven according to the previous host plants. Each group consist of ten leaf discs (1 inch each) of the particular host plant and each carry singly newly emerged female of the predatory mite. All groups were fed on nymphs of Tetranychus urticae Koch for 10 days at $25 \pm 1^{\circ} \mathrm{C}$ and $70 \pm 5$ $\% \mathrm{RH}$. . In all cases, consumed prey individuals were counted and replaced by alive ones daily. Egg deposition of the predatory mite females were recorded daily.

\section{RESULTS AND DISCUSSION}

Data obtained in Table (1) showed that feeding capacity and fecundity of Phytoseiulus persimilis fed on nymphal stages of the two - spotted spider mite $T$. urticae was highly affected by the plant texture and rearing substrates. The predatory mite individual attacked more prey nymphs on bean leaves and the feeding capacity during 10 days in the oviposition period was declined gradually on apple, fig, cotton and mango with an average of $16.37,15.92,10.28,9.95$ and 8.97 prey individuals / day, respectively (Table 1 and Fig. 1) The statistical analysis proved that there were no significant differences between the values of prey consumption of $P$. persimilis on either bean and apple leaves or fig and cotton leaves. Moreover, the differences between the aforementioned plants and the others are significant. Therefore, it can be concluded that both bean and apple leaves are more suitable substrates to rear and maintain $P$. persimilis.

These results agree with the finding of Fouly (1982) who found that Euseius scutalis (A. - H.) had a faster development and laid more eggs when it fed on $T$. urticae and kept on ficus leaves more than lantana camara leaves. Also, Rasmy (1990) found that cucumber leaves were inadequate as a rearing substrate for Euseius scutalis $(\mathrm{A}$. $-\mathrm{H}$.) but it was suitable for rearing Phytoseius finitimus Ribbaga. On the other hand, Skirvin and Williams (1999) stated that plant species had a significant effect on fecundity and movement of the prey $T$. urticae but no effect on the movement of $P$. persimilis. Phytoseiid mite species live mostly on leaf undersurface that have raised viens, dense hairs, tunneled margins and cave - like structures in the vein axils which called domatia. 
Table (1) : Effect of plant texture on feeding capacity and fecundity of Phytoseiulus persimilis fed on nymphs of Tetranychus urticae (koch) at $25^{\circ} \mathrm{C}$ and $70 \pm 5 \% \mathrm{RH}$. during 10 days

\begin{tabular}{|c|c|c|c|}
\hline \multirow{2}{*}{ Plant } & No. consumed prey & \multicolumn{2}{|c|}{ No. deposited eggs } \\
\cline { 3 - 4 } & nymphs / day $\left(\mathbf{x}^{-}\right)$ & $\mathbf{T}$ & $\mathbf{D}$ \\
\hline Bean & $16.37 \pm 0.41 a$ & 39.5 & $3.95 \pm 0.12 \mathrm{a}$ \\
\hline Apple & $15.92 \pm 0.18 a$ & 37.3 & $3.73 \pm 0.11 \mathrm{ab}$ \\
\hline Fig & $10.28 \pm 0.20 \mathrm{~b}$ & 36.1 & $3.61 \pm 0.11 \mathrm{~b}$ \\
\hline Squash & $5.91 \pm 0.21 \mathrm{e}$ & 31.5 & $3.15 \pm 0.14 \mathrm{c}$ \\
\hline Cucumber & $6.70 \pm 0.25 d$ & 30.5 & $3.05 \pm 0.12 \mathrm{c}$ \\
\hline Mango & $8.97 \pm 0.23 c$ & 25.6 & $2.56 \pm 0.08 \mathrm{~d}$ \\
\hline Cotton & $9.95 \pm 0.34 b$ & 25.1 & $2.51 \pm 0.19 \mathrm{~d}$ \\
\hline
\end{tabular}

Means in each column by a different letter are significantly different, $\mathbf{P}<0.05$ by SAS, L.S.D test.

\pm SE : Standard errors.

T : Total No. of deposited egg / 10 days.

D : Daily rate of deposited egg / days.

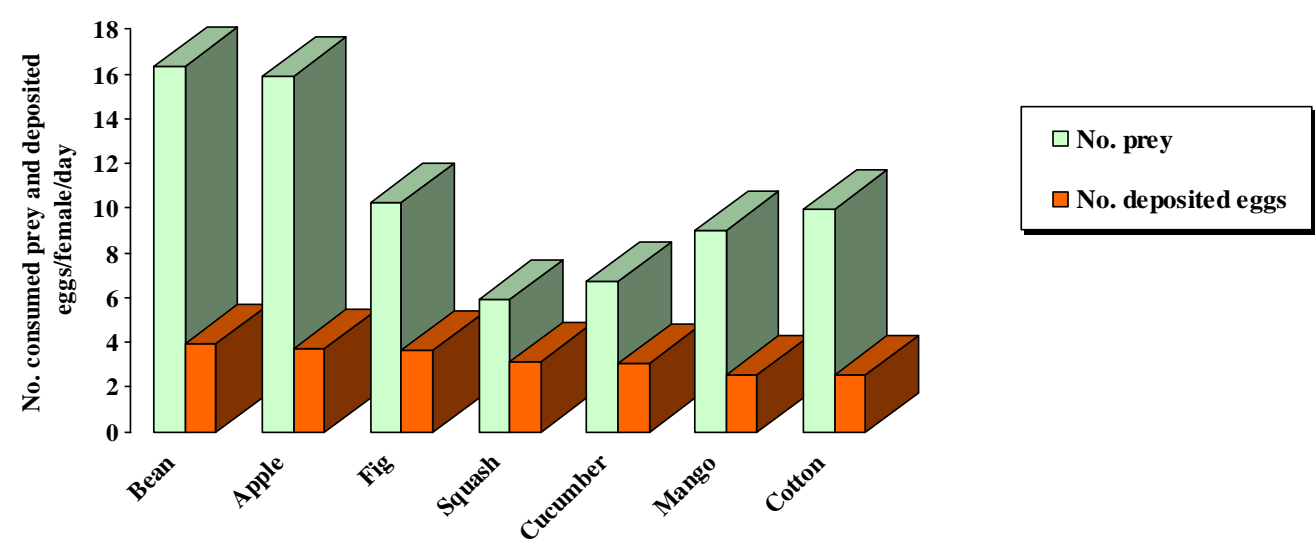

Fig 13: Effect of plant surface on feeding capacity and fecundity of Phytoseiulus persimilis females fed on Tetranychus urticae nymphs for 10 days.

These structures affect searching, feeding, mating, oviposition, hiding and other behaviours of these arthropods (Walter, 1996). Leaves with domatia often harbor more phytoseiids or greater densities of a species than leaves without domatia. Such shelters and leaf pubescence, may be as important as food for some phytoseiids (McMurtry and Croft, 1997).

In general, data showed that there were some important parameters affecting the predatory mite searching behavior such as walking speed, walking activity, leaf characteristics, and prey density. The present results clearly indicated that walking speed and activity of $P$. persimilis had a 
negative relationship where they declined when the predatory mite was reared on hairy leaves. Also, the time needed by the predator to find its prey increased when the hair density increased. That may be the reason why the feeding capacity of $P$. persimilis was lower on hairy leaves such as cucumber and squash while it was at its highest level on smooth or fine hairy leaves such beans and apple. Similar results were previously obtained by Gillespie and Quiring (1994) who found that life span and reproduction of $P$. persimilis were lower on tomato leaves than on beans Phaseolus vulgaris and the feeding capacity was higher on beans than on tomato leaves.

Also, Garms et al. (1998) found that $P$. persimilis females needed a time to prey on $T$. urticae 4 to 10 times shorter when they were kept on lima bean P. Iunatus than on gerbera leaves. Moreover, Skrivin and Fenlon (2001) stated that the leaf morphology is considered to be one of the most important factores affecting predation rate and feeding capacity for both predator and prey species. They found that $P$. persimilis attacked more prey individuals on smooth hairy leaves.

Contradicting results were obtained by Kreiter et al. (2002) who found that Kampimodromns aberrans (Oudemans) fed on tetranychid mites was highly influenced by plant texture and leaf domatia. The phytoseiid predatory mite was found to prefer leaves with pits or concentration of hairs as shelter.

Concerning the fecundity of $P$. persimilis, data in Table (1) showed that adult female preferred leaves of bean, apple and fig to lay its eggs and the egg deposition was significantly decreased when predatory mites were maintained on cucumber and squash leaves. The lowest rates of fecundity were obtained on mango and cotton leaves. Adult female laid an average of $39.5,37.3$ and 36.1 eggs / 10 days with daily rate of $3.95,3.73$ and 3.61 eggs / + / day on bean, apple and fig leaves, respectively. These values significantly decreased to an average of $3.15,3.05,2.56$ and 2.51 eggs / $q$ / day when adult females of $P$. persimilis was kept with its prey on squash, cucumber, mango and cotton leaves, respectively Table 1 and Fig. 1.

On the other hand, a comparison leaves surfaces structure might gave some light on the relationship between leaves surfaces structure and number of deposited eggs and feeding capacity of $P$. persimilis on T.urticae.

Data in Table (1) showed that structure of the leaf surfaces strongly affect the number of deposited eggs and feeding capacity of $P$. persimilis on T.urticae. Among structures on the surfaces of leaves not only the venation type and hair density but also the raised veins play an important role in number of deposited eggs of predator and its feeding capacity on prey.

It is clear from Fig. 2, the venation of all investigated plants was reticulate, some genera i. e. apple and mango has pinnate venation Fig. 2 and other plant genera i.e. Fig leaf has palmate venation Fig. 2. It is also shown that apple leaf surface characterized by more raised veins and covered with dense tufts and appressed hairs Fig. 2.

Summarizing the results in Table (2) the highest number of deposited eggs and predator feeding capacity on bean and apple leaves surfaces were correlated with high density of hairs and more raised veins. Moreover, the leaf surface of bean had shrinked leaf surface. These features might prove numerous hiding places as houses of predator. In this respect, Walter, (1996) 
noted that, on the surface of leaves numerous hiding places formed by large, raised veins, dense covering of hairs, cave like structures in the vein axils are house of arthropods. While the leaf surface of squash as a moderate feeding capacity of $P$. persimilis had a lower number with acute tips of multiseriate hairs.

On the other hand, the lower number of deposited eggs and feeding capacity of $P$. persimilis on mango leaf surface correlated with thinner veins and smooth leaf surface.

Grevstad and Klepetka (1992) concluded that lower number of the four coccinellid predators on cabbage leaves surfaces have been correlated with smooth leaf surface. The obtained results confirmed simple relationship existing between the surface of investigated leaves and number of deposited eggs of predator as well as feeding capacity of $P$. persimilis on $T$. urticae.

Table (2): Relationship between leaf surface structure and number of deposited eggs and feeding capacity of $P$. persimilis on $T$. urticae.

\begin{tabular}{|c|c|c|c|c|c|}
\hline Plant & $\begin{array}{c}\text { No. of hairs per } \\
\text { microscopic field } \\
\text { (obj. x10. oc. x10) }\end{array}$ & $\begin{array}{c}\text { Venation } \\
\text { type }\end{array}$ & Hairs type & $\begin{array}{c}\text { No. of } \\
\text { deposited eggs } \\
\text { per female / 10 } \\
\text { fays }\end{array}$ & $\begin{array}{c}\text { Feeding } \\
\text { capacity }\end{array}$ \\
\hline Bean & 40 & Palmate & Uniseriate hairs & 39.5 & High \\
\hline Apple & 35 & Pinnate & Uniseriate tufts hairs & 37.3 & High \\
\hline Fig & 30 & Palmate & Uniseriate tufts hairs & 36.1 & Moderate \\
\hline Squash & 17 & Palmate & Multiseriate hairs & 31.5 & Moderate \\
\hline Cucumber & 27 & Palmate & Multiseriate hairs & 30.5 & Moderate \\
\hline Mango & 0 & Pinnate & Without hairs & 25.6 & Low \\
\hline Cotton & 10 & Palmate & Branched uniseriate hairs & 25.1 & Low \\
\hline
\end{tabular}

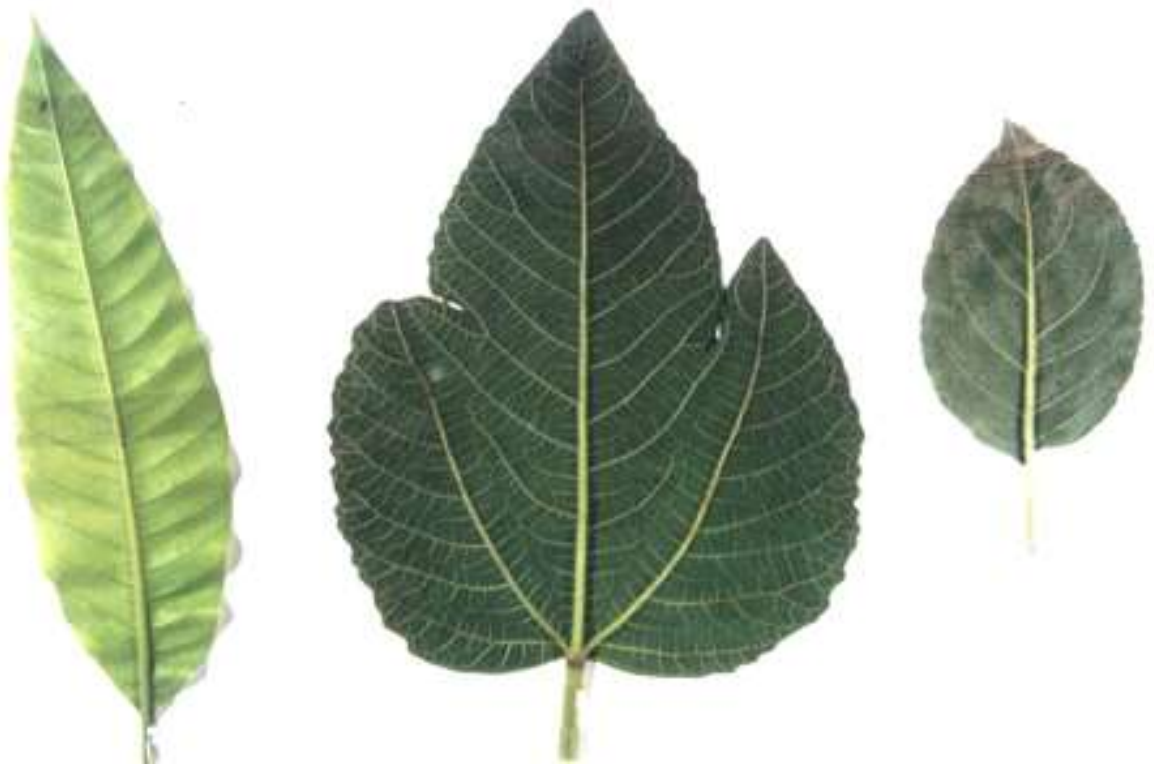

Fig. (2): Venation type in some investigated plants (obj. x 10. oc. x10). 
From the previous results, it can be noticed that $P$. persimilis attacked more prey individuals and laid more eggs on smooth hairy leaves like bean and apple plant while cucumber, squash and cotton leaves were not suitable substrates to get high populations of the predatory mite. Therefore, it is highly recommended to use such plant leaves to maintain $P$. persimilis for biological control purposes. Similar results were obtained by Gillespie and Quiring (1994) who found that reproduction which is turned in high rates of fecundity of $P$. persimilis fed on $T$. urticae was obtained on bean leaves more than on tomato leaves.

In conclusion, many questions remain about adaptations of phytoseiid mites to plant attributes. For example, how does leaf structure allow some phytoseiid species to colonize on a plant while others not? Can two or more species cohabit a leaf by habitat portioning? If so, do some refuges minimize interspecific competition more than others? Answers to the aforementioned questions have implications for biological control.

Phytoseiid mites may show inconsistent control of pest mites but, in general, few studies have examined how host plant traits influence control (Walter, 1996).

\section{REFERENCES}

Fouly, A. H. (1982).Studies on Phytoseiid mites.M. Sc. Thesis, Fac. Agric., Mansoura Univ., Egypt.

Garms, L. M.; Krips, O. E.; Schutte, C. and Dicke, M. (1998).The ability of the predatory mite Phytoseiulus persimilis to find a prey colony:effect of host plant species and herbivore induced volatiles. Proceedings of the Section Experimental and Applied Entomology of theNetherlands Entomological Society. 9: 67-72.

Gillespie, D. R. and Quiring, D. J. M. (1994).Reproduction and longevity of the predatory mite, Phytoseiulus persimilis (Acari: Phytoseiidae) and its prey, Tetranychus urticae(Acari: Tetranychidae) on different host plants. Journal of the Entomological Society of British Columbia. 91: 38.

Grevstad, F.S. and Klepetka, B.W. (1992). The influence of plant architecture on the foraging efficiencies of a suite of ladybird beetles feeding on aphids. Oecologia 92(3): 399-404.

Kreiter, S.; Tixier, M.-S.; Croft B. A.; Auger, P. AND Barret, D. (2002).Plants and Leaf Characteristics Influencing the Predaceous Mite Kampimodromus aberrans (Acari: Phytoseiidae) in Habitats Surrounding Vineyards. Environ. Entomol. 31(4): 648 - 660 (2002)

McMurtry, J.A. and Croft, B.A. (1997). Life-styles of phytoseiid mites and their roles in biological control. Annu. Rev. Entomol. 42: 291-321.

Rasmy, A. H.; Abdel-Rahman, H. A. and Hussein, H. E. (1990).Biology and efficiency of phytoseiid mites as affected by cucumber leaves.Anzeiger fur Schadlings kunde, Pflanzenschutz, Umweltschutz. 63: 6: 117 - 116 
Skirvin, D. and Williams, M. de C. (1999).The effect of plant species on the biology of Tetranychus urticae and Phytoseiulus persimilis.Bulletin OILB/SROP. International Organization for Biological and Integrated Control of Noxious Animals and Plants (OIBC/OILB), West Palaearctic RegionalSection (WPRS/SROP), Dijon, France: 22: 1, 233-236.

Walter D. E. (1996).Living on leaves: Mites, tomenta and leaf domatia. Annu. Rev. Entomol. 41, 101-114.

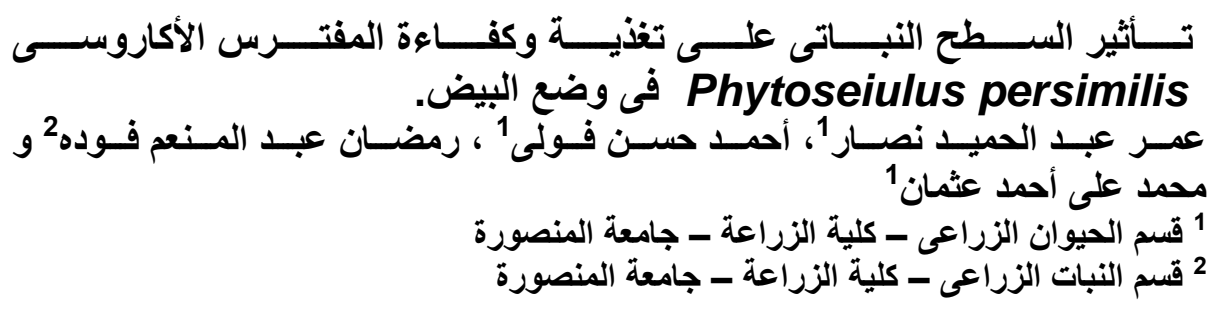

تمت دراسة تأثثر السطح النباتى على تغذية وكفاءة المفترس الأكاروسى أنى Phytoseiulus persimilis

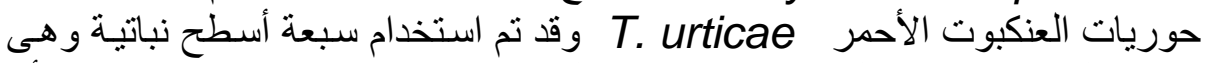

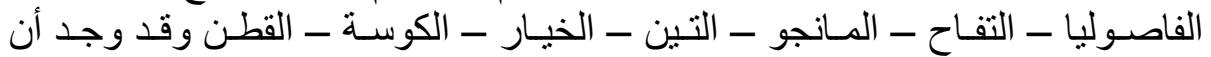

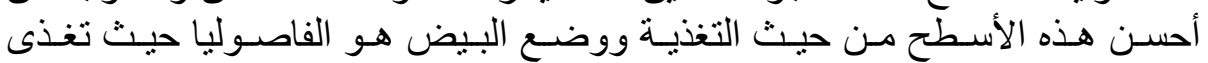
المفترس على 16.37 حورية من العنكبوت الأحمر في اليوم الواحت العد و أعطى 3.95

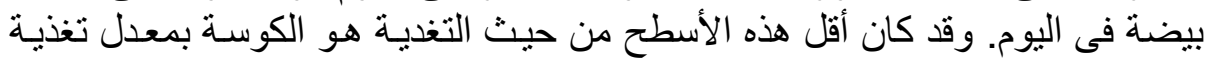

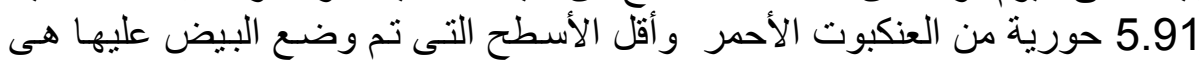
القطن حيث وضعت أنثى المفترس 2.51 بيضة في الإنى اليوم.

كلية الزراعة - جامعة المنصورة قام بتحكيم البحث كلية الزراعة - جامعة الأزهر أ.د / أحمد جمال الثريف البحث أ.د / عبد الستار ابراهيم متولى الثريف 